\title{
Novel Ethylene/Norbornene Copolymers as Nonreleasing Antioxidants for Food-Contact Polyolefinic Materials
}

\author{
Paola Stagnaro, ${ }^{1}$ Giorgio Mancini, ${ }^{1}$ Achille Piccinini, ${ }^{2}$ Simona Losio, ${ }^{2}$ Maria Carmela Sacchi, ${ }^{2}$ \\ Caterina Viglianisi, ${ }^{3}$ Stefano Menichetti, ${ }^{3}$ Alessandro Adobati, ${ }^{4}$ Sara Limbo ${ }^{4}$ \\ ${ }^{1}$ Institute for Macromolecular Studies ISMAC-CNR, Via De Marini 6, 16149 Genova, Italy \\ ${ }^{2}$ Institute for Macromolecular Studies ISMAC-CNR, Via Bassini 15, 20133 Milano, Italy \\ ${ }^{3}$ Department of Chemistry "U. Schiff," University of Florence, Via della Lastruccia 13, 50019 Sesto Fiorentino (FI), Italy \\ ${ }^{4}$ Department of Food, Environmental and Nutritional Sciences DeFENS, University of Milan, Via Celoria 2, 20133, Milano, Italy \\ Correspondence to: P. Stagnaro (E-mail: stagnaro@ge.ismac.cnr.it) or S. Limbo (E-mail: sara.limbo@unimi.it)
}

Received 10 April 2013; accepted 11 April 2013; published online 8 May 2013

DOI: 10.1002/polb.23304

ABSTRACT: An efficient procedure for the copolymerization of ethylene (E) with a novel norbornenic comonomer $\left(\mathrm{N}_{\mathrm{ArOH}}\right)$ bearing a stabilizing moiety analogous to commercial antioxidant 2,6-di-tert-butyl-4-methylphenol (BHT) is successfully developed. This study is aimed at: i) tuning the concentration of the stabilizing function along the polymer chain, and ii) preparing "nonreleasing" polymeric additives specifically destined to protect commercial low-density polyethylene (LDPE). Films obtained from blends of the novel $\mathrm{E} / \mathrm{N}_{\mathrm{ArOH}}$ copolymers with an antioxidant-free LDPE matrix are characterized by superior thermal, thermo-oxidative, and photostability when compared not only with neat LDPE films but also with films stabilized by the commercial BHT additive. Specific migration tests conducted in order to investigate the nonreleasing character of the novel macromolecular additives confirm the reduced risk of migration, from the films into food simulants, of unreacted comonomer or degradation products bearing the antioxidant moiety. (c) 2013 Wiley Periodicals, Inc. J. Polym. Sci., Part B: Polym. Phys. 2013, 51, 1007-1016

KEYWORDS: antioxidants; blends; food packaging; macromolecular antioxidants; migration; thermogravimetric analysis (TGA)
INTRODUCTION Sterically hindered phenols (ArOH) are among the oldest and most important class of antioxidants used for stabilizing commercial polyolefins. ${ }^{1,2}$ Even though the mechanism of radical chain oxidation of hydrocarbon polymers is rather complex and far from being completely unravelled, ${ }^{3}$ it is commonly accepted that hindered phenols operate by trapping peroxyl radicals more efficiently than the polymeric substrate $(\mathrm{RH})$, eqs 1 and 2, thereby breaking the radical chain oxidation reaction.

$$
\begin{gathered}
\mathrm{ROO} \bullet+\mathrm{ArOH} \rightarrow \mathrm{ROOH}+\mathrm{ArO} \bullet \\
\mathrm{ROO} \bullet+\mathrm{RH} \rightarrow \mathrm{ROOH}+\mathrm{R} \bullet
\end{gathered}
$$

A limiting factor in the usefulness of such antioxidants in polymers is their physical loss through diffusion with subsequent volatilization or extraction. ${ }^{1(\mathrm{~b}, \mathrm{c})}$ Many attempts to overcome this problem have been reported and, indeed, the most challenging approach to increase the persistence of an antioxidant in the polymeric matrix was the preparation of polymer-bound antioxidant systems. ${ }^{4}$ Within the field of polyolefinic materials, such an approach underwent an important breakthrough in the early nineties due to the discovery that sterically hindered phenols, in the presence of metallocene based systems, do not poison the catalytic centers, and, in combination with methylaluminoxane (MAO) cocatalyst, can even act as polymerization activators. ${ }^{5}$ Such a discovery paved the way to the synthesis of polymeric antioxidants through the copolymerization of ethylene or propylene with comonomers bearing the antioxidant phenolic functionality and an easily polymerizable double bond, in the presence of suitable metallocene catalysts.

Nowadays, there is an increasing demand for new "tailor made" functional polymeric materials for potential applications in specific fields, such as packaging, optical devices, and medical applications. In this respect, polyolefins, which combine low price and easy processing and are endowed with good mechanical and optical properties in addition to their characteristics of nontoxicity and chemical inertia, certainly constitute a family of promising candidates for a spread of applications in the abovementioned fields. The use of metallocene catalysts offered us the possibility of tailoring the structure of the antioxidant polymeric additives specifically destined to protect the different families of commodity 


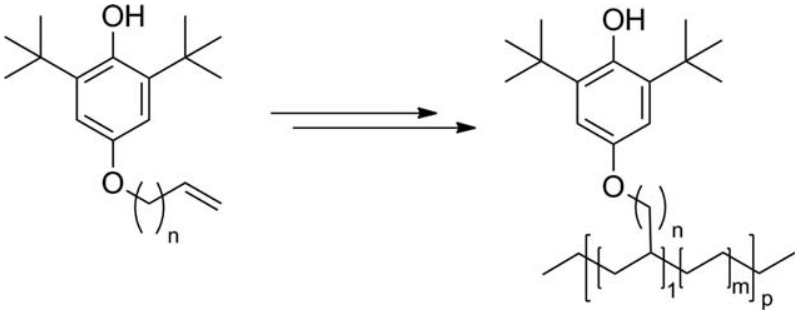

SCHEME 1 BHA inspired comonomers and copolymers.

and/or niche polymers. Indeed, using a polymeric additive prepared ad hoc for a particular polyolefinic material is expected to ensure a better compatibility with the polymeric matrix, with consequent better distribution in the bulk of the functional units.

Recently, we reported the preparation of olefinic comonomers (Scheme 1) bearing a highly efficient antioxidant function, similar to the common commercial antioxidant 2,6-ditert-butyl-4-methoxyphenol (BHA), and capable of easily copolymerizing in variable and tunable amounts with ethylene to give random copolymers (Scheme 1). ${ }^{6}$

These copolymers were melt-blended with an antioxidantfree commercial low-density polyethylene (LDPE), commonly used in food packaging applications. Films obtained by compression molding, when tested for their thermal and thermooxidative stability by TGA analysis, showed a longer induction time before $\mathrm{O}_{2}$ up-take starts and, consequently, a higher degradation temperature than neat LDPE or LDPE containing the low molecular weight commercial additive BHA. Ageing tests demonstrated that the new polymeric antioxidants exert also a valid protection against photo-oxidation. Finally, migration tests revealed the absence of any trace of products containing the antioxidant moiety when the films were kept in contact with a food simulant. ${ }^{7}$

Such successful results encouraged us to explore a feasible synthetic route for the preparation of a novel comonomer $\left(\mathrm{N}_{\mathrm{ArOH}}\right)$ in which a stabilizing function similar to the commercial antioxidant 2,6-di-tert-butyl-4-methylphenol (BHT) is bound to a norbornene (N) skeleton (Scheme 2). ${ }^{8}$ Norbornene was chosen since it is proved to be an extremely effective monomer in polymerization with metallocene based catalysts. ${ }^{9}$ Moreover, the synthesis of functionalized norbornene comonomers appears quite interesting for the preparation of nonreleasing additives designed to protect polyethylene, and, in perspective, specifically suitable for commercial ethylene-norbornene copolymers (trade name: TOPAS $($ ), a package material particularly used for pharmaceuticals with high added value. ${ }^{10}$

In a preliminary report, the synthesis of $\mathrm{N}_{\mathrm{ArOH}}$ comonomer and selected functionalized copolymers were described. ${ }^{8}$ In this article, the development of the copolymerization procedure aimed at tuning the concentration along the chain of the stabilizing function and, in the meantime, at obtaining sufficient amounts of the polymeric additives for the successive characterization and testing of the ensuing materials is described. The conditions for the effectiveness of this new family of polymeric additives in protecting the polyolefinic matrix are explored. Films obtained by compression molding of the blends prepared by melt mixing of the novel copolymers with an antioxidant-free LDPE matrix were analyzed in terms of thermal, thermo-oxidative, and photostability and compared with LDPE films containing the commercial BHT additive. Investigations on the nonreleasing character of these macromolecular additives are reported as well.

\section{EXPERIMENTAL}

Comonomer $\mathrm{N}_{\text {ArOH }}$ was prepared and its exo/endo structural determination obtained as recently reported. ${ }^{8}$ In particular, the copolymers used in this article were prepared using $\mathrm{N}_{\mathrm{ArOH}}$ comonomer samples with exo/endo ratios of $1.1 / 1$ and $6 / 1$, respectively.

All experiments and manipulations involving air-sensitive compounds were carried out under dry nitrogen atmosphere in glovebox or by using standard Schlenk line techniques. MAO (10 wt \% as toluene solution, Crompton) was used after removing all volatiles and drying the resulting powder at $50{ }^{\circ} \mathrm{C}$ for $3 \mathrm{~h}$ in vacuum (0.1 mmHg). Triisobutylaluminum (TIBA) (Witco, in solution of toluene) was used as received. rac-Et(Ind) $)_{2} \mathrm{ZrCl}_{2}$ catalyst was provided by Lyondellbasell Italia S.r.l.. Toluene was dried and distilled from sodium under nitrogen atmosphere. Nitrogen and ethylene gases were dried and deoxygenated by passage over columns of $\mathrm{CaCl}_{2}$, molecular sieves, and BTS-catalyst.

\section{Typical Copolymerization Procedure}

The copolymerizations were performed in a round-bottom flask at $30{ }^{\circ} \mathrm{C}$ and 1.0 or 0.5 atm of ethylene gas pressure. The total volume of toluene $(100 \mathrm{~mL})$ was introduced into the evacuated and $\mathrm{N}_{2}$ purged flask. The synthesized comonomer was added with TIBA (ratio between TIBA and comonomer $=1.2$ ) and the solution was stirred for $2 \mathrm{~h}$ under a positive $\mathrm{N}_{2}$ pressure. Afterward the flask was filled with 6 mmol of MAO solution, $2 \mu \mathrm{mol}$ of the catalyst (ratio between $\mathrm{Zr}$ and $\mathrm{Al}=3000$ ). The ratio between ethylene and the comonomer was maintained with the correct proportion of $\mathrm{N}_{2}$ and ethylene gas in the flask. The copolymerization was stopped after due time through the addition of ethanol and $\mathrm{HCl}$. The reaction product was stirred for several hours then filtered, washed with ethanol, and dried in vacuum. The general structure of the copolymers is sketched in Scheme 3 and their main features are summarized in Table 1.

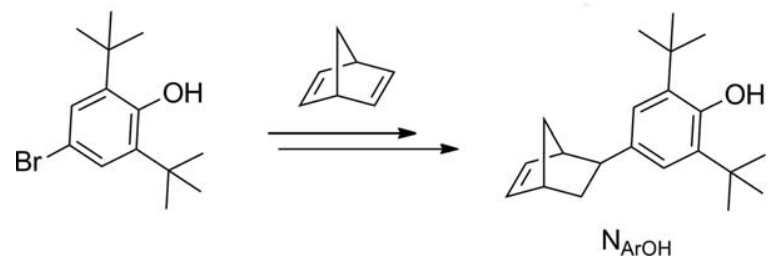

SCHEME 2 BHT/Norbornene $\mathrm{N}_{\mathrm{ArOH}}$ inspired comonomer. 


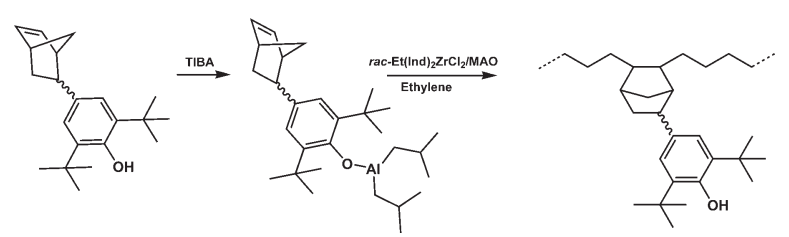

SCHEME 3 Ethylene/ $\mathrm{N}_{\text {ArOH }}$ copolymerization procedure.

\section{${ }^{13}$ C NMR Characterization of Copolymers}

The amount of bound phenolic stabilizers was determined by ${ }^{13} \mathrm{C}$ NMR analysis. The spectra of the copolymers were recorded in $\mathrm{CDCl}_{2} \mathrm{CDCl}_{2}$ at $103{ }^{\circ} \mathrm{C}$ on a Bruker Avance 400 spectrometer operating at $100.58 \mathrm{MHz}$, internal chemical shift reference: 1\% hexamethyldisiloxane. Because of the low solubility of the copolymers, the samples $(50 \mathrm{mg}$ of copolymer in $2.5 \mathrm{~mL}$ of $\mathrm{CDCl}_{2} \mathrm{CDCl}_{2}$ ) were stirred at $100{ }^{\circ} \mathrm{C}$ for $24 \mathrm{~h}$ before recording the spectrum. The complete signal assignment and the equations to calculate the comonomer content in the produced copolymers are reported in Ref. 8. Phenolic comonomer homosequences were not detected in the spectra, suggesting that the obtained products are random copolymers containing only isolated comonomer units. No detectable traces of unreacted phenolic comonomers were found in the olefinic region of the spectra.

\section{DSC Analysis of Copolymers}

Melting and crystallization behavior of the synthesized copolymers was analyzed by differential scanning calorimetry (DSC) using a Mettler DSC $821^{\mathrm{e}}$ instrument (scanning rate $10{ }^{\circ} \mathrm{C} \min ^{-1}$, under nitrogen). All samples were treated as follows: after destroying the nascent crystallinity at 180 ${ }^{\circ} \mathrm{C}$, the specimens were cooled down to $-100{ }^{\circ} \mathrm{C}$, and the exothermal signal associated to crystallization was recorded. A second heating up to $180{ }^{\circ} \mathrm{C}$ was imposed to acquire information on the melting behavior.

\section{Preparation of Blends and Films}

As a polymer matrix was chosen a commercial LDPE (Lupolen LP $2420 \mathrm{~F})^{11}$ supplied by Lyondelbasell Italia S.r.l.
Lupolen LP $2420 \mathrm{~F}$ is a nonadditivated, low density polyethylene [density $0.923 \mathrm{~g} \mathrm{~cm}^{-3}$; MFR $\left(190{ }^{\circ} \mathrm{C}, 2.16 \mathrm{~kg}\right) 0.75 \mathrm{~g}$ $(10 \mathrm{~min})^{-1}$; melting temperature $111{ }^{\circ} \mathrm{C}$ ] containing about $1.5 \mathrm{~mol} \%$ of 1-hexene comonomer and rare long branches. 2,6-di-tert-butyl-4-methylphenol (butylhydroxy toluene, BHT) was purchased from Sigma Aldrich (Italy).

Blends of the additive-free LDPE and the synthesized copolymers were prepared by melt-blending in an internal batch mixer (Brabender W50 EHT Plasti-Corder ${ }^{\circledR}$ ) operating at 130 ${ }^{\circ} \mathrm{C}$ and $50 \mathrm{rpm}$ for $15 \mathrm{~min}$ under $\mathrm{N}_{2}$. In order to have 500 ppm of antioxidant moieties dispersed into the polyethylene matrix, a proper amount of copolymer was used for each blend, taking into account the specific copolymer composition. The value of 500 ppm was chosen, because it is a typical amount of antioxidant added to stabilize polyolefinic materials. Neat LDPE and its mixtures with 500 and 2000 ppm of commercial BHT antioxidant were treated under identical processing conditions and used for reference purposes.

To ensure correct sampling, thus optimizing reproducibility and reliability of the successive TGA, sheets with thickness of about $400 \mu \mathrm{m}$ were obtained from the blends by compression molding with a P $200 \mathrm{E}$ semiautomatic laboratory press (Collin) operating at $160{ }^{\circ} \mathrm{C}$; discs of $5 \mathrm{~mm}$ diameter, that is, with constant surface area and weight, were then punched from the sheets. About $100-\mu \mathrm{m}$ thick films of $11 \times 11 \mathrm{~cm}^{2}$ were also prepared by compression molding at $160{ }^{\circ} \mathrm{C}$ and used for successive ageing and migration tests.

\section{MFR Measurements}

Melt flow rate (MFR) measurements were carried out by using a CEAST $^{\circledR}$ Modular Melt Flow Index Tester Model 7024.000, which provided MFR and melt volume rate (MVR) values, expressed, respectively, in grams and in $\mathrm{cm}^{3}$ of flown material per $10 \mathrm{~min}$. Measurements were performed at 190 ${ }^{\circ} \mathrm{C}$ with a weight load of $2.16 \mathrm{~kg}$ (ASTM D1238), following the IS01133A standard procedure, on pellets of the original purchased LDPE matrix and on the same material after meltblending treatment.

TABLE 1 Ethylene/ $\mathrm{N}_{\mathrm{ArOH}}$ Copolymerizations with rac-Et(Ind) ${ }_{2} \mathrm{ZrCl}_{2}$ and $\mathrm{MAO}$ as Catalytic System ${ }^{\mathrm{a}}$

\begin{tabular}{|c|c|c|c|c|c|c|c|c|c|c|c|c|}
\hline Run & {$\left[\mathrm{C}_{2} \mathrm{H}_{4}\right] /[\mathrm{com}]$} & $\begin{array}{l}\text { Comonomer } \\
{[\mathrm{mmol}-} \\
(\text { exo/endo })]^{\mathrm{b}}\end{array}$ & $\begin{array}{l}P_{\mathrm{E}} \\
\text { (atm) }\end{array}$ & $\begin{array}{l}t \\
(\min )\end{array}$ & $\begin{array}{l}\text { Yield } \\
\text { (mg) }\end{array}$ & Activity $^{c}$ & $\begin{array}{l}\text { Conver. } \\
(\%)\end{array}$ & $\begin{array}{l}\text { Incorporated } \\
\text { Comonomer } \\
{[\mathrm{mol} \%-(\text { exo/endo })]^{\mathrm{b}}}\end{array}$ & $T_{\mathrm{c}}^{\left.\mathrm{d}{ }^{\circ} \mathrm{C}\right)}$ & $\begin{array}{l}\Delta H_{\mathrm{c}}^{\mathrm{d}} \\
\left(\mathrm{J} \mathrm{g}^{-1}\right)\end{array}$ & $\begin{array}{l}T_{\mathrm{m}}{ }^{\mathrm{e}} \\
\left({ }^{\circ} \mathrm{C}\right)\end{array}$ & $\begin{array}{l}\Delta H_{\mathrm{m}}{ }^{\mathrm{e}} \\
\left(\mathrm{J} \mathrm{g}^{-1}\right)\end{array}$ \\
\hline 1 & - & - & 1 & 30 & 1,800 & 1,800 & - & - & 118 & -181 & 134 & 192 \\
\hline 2 & 26.68 & $0.5-(1.1 / 1)$ & 1 & 20 & 1,958 & 2,938 & 18 & $0.13-(3 / 2)$ & 129 & -171 & 129 & 172 \\
\hline 3 & 13.34 & $1-(1.1 / 1)$ & 1 & 20 & 2,580 & 3,870 & 30.9 & $0.35-(3 / 2)$ & 113 & -152 & 128 & 155 \\
\hline 4 & 6.67 & $1-(1.1 / 1)$ & 0.5 & 25 & 1,320 & 3,168 & 28.8 & $0.65-(3 / 2)$ & 111 & -129 & 124 & 143 \\
\hline 5 & 13.34 & $0.5-(6 / 1)$ & 0.5 & 15 & 390 & 1,560 & 20.1 & $0.78-(9 / 1)$ & 109 & -130 & 121 & 136 \\
\hline 6 & 3.35 & $2-(1.1 / 1)$ & 0.5 & 30 & 1,420 & 2,840 & 35.2 & $1.60-(3 / 2)$ & 90 & -79 & 109 & 84 \\
\hline \multicolumn{7}{|c|}{$\begin{array}{l}\text { a } \text { Copolymerization conditions: solvent }=\text { toluene; } V_{\text {tot }}=100 \mathrm{~mL} \text {; cata- } \\
\text { lyst }=2 \mu \mathrm{mol} ;[\mathrm{Al}] /[\mathrm{Zr}]=3,000 ;[\text { com }] /[\mathrm{TIBA}]=1: 1.2 ; T=30{ }^{\circ} \mathrm{C} \text {. } \\
\text { b Determined by }{ }^{13} \mathrm{C} \text { NMR. } \\
{ }^{\mathrm{c}} \text { Defined as } \mathrm{g}_{\mathrm{pol}} / \mathrm{mmol}_{\text {cat.h.PE. }}\end{array}$} & \multicolumn{6}{|c|}{$\begin{array}{l}\text { d Determined by DSC on cooling. } \\
\text { e Determined by DSC on second heating. }\end{array}$} \\
\hline
\end{tabular}




\section{TGA Analysis}

Thermal and thermo-oxidative stabilities of copolymers and blends were tested by TGA experiments performed, respectively, under $\mathrm{N}_{2}$ and $\mathrm{O}_{2}$ atmosphere using a PerkinElmer TGA7 instrument. TGA measurements were carried out both in dynamic and isothermal conditions. In the dynamic mode, the explored temperature range was $50-700{ }^{\circ} \mathrm{C}$ (heating rate $20{ }^{\circ} \mathrm{C} \min ^{-1}$ ). Isothermal experiments were carried out by rapidly reaching 130 or $180{ }^{\circ} \mathrm{C}$ under $\mathrm{N}_{2}$ atmosphere; after $10 \mathrm{~min}$, the purge gas was switched to oxygen to start the oxygen induction time (OIT) measurements (the instant in which oxygen enters the instrument furnace was referred as $t_{0}$ in the following). To guarantee the comparison and reproducibility of the OIT experimental results, the isothermal measurements were carried out, as specified above, on film specimens with the same weight and the same surface area exposed to the oxygen action. The isothermal TGA traces are the mean curves resultant from at least four different experiments carried out for each examined sample.

\section{Thermoageing and Photoageing Tests}

Thermoageing tests were carried out by maintaining film specimens $\left(2 \times 4 \mathrm{~cm}^{2}\right)$ into a thermostated oven at $70 \pm 1$ ${ }^{\circ} \mathrm{C}$ for 75 days. During storage samples were analyzed by means of Fourier transform infrared spectroscopy (FTIR) (Spectrum 100, PerkinElmer) in normal transmission mode (32 scans, resolution $4 \mathrm{~cm}^{-1}$, wave number range 4000-400 $\mathrm{cm}^{-1}$ ) to monitor the evolution of carbonyl groups, as previously described. ${ }^{7(a)}$

For photoageing tests, film samples $\left(2 \times 4 \mathrm{~cm}^{2}\right)$ were placed horizontally onto a turntable and exposed to constant illumination produced by a $300-\mathrm{W}$ Osram-Ultra Vitalux ${ }^{\circledR}$ lamp. The lamp was placed $35 \mathrm{~cm}$ above the turntable with incident beam at $30^{\circ}$. The sample temperature, recorded by means of data loggers (Smart Reader SR04), was $74 \pm 4{ }^{\circ} \mathrm{C}$. Irradiance at sample level was measured using a portable digital photoradiometer (Delta Ohm HD2102.2) equipped with specific probes. The recorded irradiance values were $200 \pm 20,36$ \pm 4 , and $10 \pm 3 \mathrm{~W} \mathrm{~m}^{-2}$ in the visible, UVA, and UVB regions, respectively. At different times, the FTIR analysis was performed on films in normal transmission mode (32 scans, resolution $4 \mathrm{~cm}^{-1}$, wave number range 4000 $\left.400 \mathrm{~cm}^{-1}\right){ }^{7(\mathrm{a})}$

\section{Specific Migration Tests}

Specific migration tests were carried out on films by using the total immersion procedure with a ratio of $0.6 \mathrm{dm}^{2}$ of food contact area to $100 \mathrm{~mL}$ of two food simulants, namely, ethanol at 95\% v/v and pure 2,2,4-trimethylpentane (ACS reagent, purity $>99 \%$ ). The migration test conditions were as follows:

a. Immersion in $95 \%$ ethanol at $40{ }^{\circ} \mathrm{C}$ for 10 days;

b. Immersion in $95 \%$ ethanol at $70{ }^{\circ} \mathrm{C}$ for 2 days;

c. Immersion in 2,2,4-trimethylpentane at $20^{\circ} \mathrm{C}$ for 2 days.
The migration tests under (a) and (c) conditions were carried out both on irradiated (300-W Osram-Ultra Vitalux ${ }^{\circledR}$ lamp, 2 days of exposure) and nonirradiated films.

After the contact time elapsed, the simulants were dried at $40{ }^{\circ} \mathrm{C}$ in a rotary evaporator. ${ }^{12}$ The residue was recovered by dissolution in $2 \mathrm{~mL}$ of $n$-hexane (Sigma Aldrich), and $2 \mu \mathrm{L}$ of the solution was analyzed by a gas chromatograph (GC), (AutoSystem XL, PerkinElmer), equipped with a quadrupole mass spectrometer (MS), (TurboMass, PerkinElmer) with an electron impact (EI) ion source detector, operating at $70 \mathrm{eV}$ in full scan mode (from 40 to $400 \mathrm{~m} / \mathrm{z}$ ) and in selected ion monitoring (SIM) mode. The temperature of the transfer line and that of the ion source were set at $250{ }^{\circ} \mathrm{C}$. The research of migrated BHT and unreacted comonomer were made in SIM mode (considering the fragmentation ions $\mathrm{m} / z 205$ and $m / z 217$, respectively). The quantifications of the substances (BHT and unreacted $\mathrm{N}_{\mathrm{ArOH}}$ comonomer) were made using the external calibration curves (limit of detection (LOD), equal to 0.23 and $0.68 \mu \mathrm{g} \mathrm{mL}^{-1}$, respectively). The analysis of unknown chromatographic peaks possibly relative to degradation products bearing the antioxidant moiety was done using a GC-MS mass spectra library (National Institute of Standards and Technology, NIST MS Search v.2.0).

\section{RESULTS AND DISCUSSION}

\section{Ethylene $/ \mathbf{N}_{\text {ArOH }}$ Copolymerization}

A series of copolymerizations of ethylene and 4-(bicyclo[2.2.1] hept-5-en-2-yl)-2,6-di-tert-butylphenol $\left(\mathrm{N}_{\mathrm{ArOH}}\right)$ was conducted in the presence of MAO-activated racEt(Ind) ${ }_{2} \mathrm{ZrCl}_{2}$ catalyst. The copolymerization procedure is sketched in Scheme 3.

An ethylene homopolymer was also prepared, under the same polymerization conditions, as a reference point. The aim was to develop the copolymerization procedure and to settle the conditions suitable to tune the comonomer content up to about $2 \mathrm{~mol} \%$ since higher concentrations of the comonomer caused a poor miscibility of the copolymer with the polyolefinic matrix. ${ }^{13}$ Tri-isobutylaluminum (TIBA) was used for protecting the functional units to prevent the catalyst deactivation. ${ }^{6-8}$ It was previously pointed out how the synthesized exo- $\mathrm{N}_{\mathrm{ArOH}}$ was not stereostable on standing, ${ }^{8}$ since a variable amount of the endo- $\mathrm{N}_{\mathrm{ArOH}}$ isomer was formed keeping exo- $\mathrm{N}_{\text {ArOH }}$ either in solution or as pure compound. Two different supplies of synthesized $\mathrm{N}_{\mathrm{ArOH}}$ were used in the present work, characterized by different isomeric mixture (exo/endo equal to $1.1 / 1$ and $6 / 1$, respectively).

A compromise between the desired good yield and a moderate comonomer conversion was searched, aiming at obtaining sufficient amounts of material and, in the meantime, ensuring a relatively uniform comonomer composition. The polymerization times were regulated to contain the conversions of the functionalized comonomer up to about $35 \%$, since a conversion higher than that would do not guarantee the absence of polyethylene chains. Copolymerization conditions and results are presented in Table 1. 
The copolymerization results confirm the activating effect exerted by the hindered phenols on the polymerization rate: the copolymerization activity is in general noticeably higher (in run 3 is even more than twice) than that of homopolymerization. It is possible, to a certain extent, to tune the comonomer content within the desired composition range by varying the ethylene/comonomer molar ratio (from 26.68 to 3.35) in the reaction mixture. We can observe that the exo/endo ratio of the comonomer also greatly affects the comonomer incorporation. In general exo-substituted norbornenes are reported to be more reactive than the endo-isomers in the polymerization reaction. ${ }^{9}$ Indeed, we have observed a definite difference in incorporation among the $6 / 1$ and $1.1 / 1$ comonomer samples. ${ }^{8}$ The results of runs 3 and 5 of Table 1 , conducted at the same $\left[\mathrm{C}_{2} \mathrm{H}_{4}\right] /[\mathrm{com}]$ ratio $(13.34)$, show that the $6 / 1$ exo/endo mixture is about twice more reactive than the $1.1 / 1$ one.

Because of the low solubility of all the produced copolymers even in high boiling solvents, such as trichlorobenzene, their molecular weights could not be accurately measured. However, they are expected to be quite high, presumably higher than that of the polyethylene reference obtained under the same polymerization conditions $\left(6.8 \times 10^{5} \mathrm{~g} \mathrm{~mol}^{-1}\right)$. The molecular weights of the copolymers likely increased due to the activation effect exerted by the phenolic comonomer on the propagation rate.

The thermal behavior of the copolymers was investigated by DSC analysis. In particular, the values of crystallization and melting temperatures ( $T_{\mathrm{c}}$ and $T_{\mathrm{m}}$ respectively) as well as those of the corresponding crystallization and melting enthalpies $\left(\Delta H_{\mathrm{c}}\right.$ and $\left.\Delta H_{\mathrm{m}}\right)$ are also reported in Table 1 . The DSC traces (not shown) recorded during the second heating run, that is, immediately after cooling from the melt at a rate of $-10{ }^{\circ} \mathrm{C} \min ^{-1}$, exhibited, as expected, a progressive shift of the single melting endotherm toward lower temperatures on increasing the content of the bulky $\mathrm{N}_{\mathrm{ArOH}}$ comonomer, even though the range of explored composition is narrow, being the maximum comonomer content equal to $1.60 \mathrm{~mol}$ $\%$. A similar trend is observed for the crystallization temperatures recorded on cooling, while the related enthalpy values consistently reduce due to the penalty effect brought about by the bulky norbornenic comonomer (Table 1 ).

Both the thermal and thermo-oxidative stability of the synthesized $\mathrm{E} / \mathrm{N}_{\mathrm{ArOH}}$ copolymers, tested by dynamic TGA experiments carried out, respectively, under nitrogen and pure oxygen atmosphere, show a general behavior pretty similar to that already observed in our previous works on ethylenebased copolymers bearing pendant moieties analogous of BHA antioxidant, where the comonomer content increased up to $8 \mathrm{~mol} \mathrm{\%}{ }^{6}$

\section{Blends and Films}

Selected $\mathrm{E} / \mathrm{N}_{\mathrm{ArOH}}$ copolymers were melt-blended in an internal batch mixer with an additive-free commercial LDPE matrix. As described in the experimental section, the copolymers were added to the LDPE matrix in proper amounts (taking into account their compositions) in order to have, in the resultant blend, a final content of 500-ppm antioxidant functionalities. Specifically, within the series of synthesized copolymers three samples (runs 3, 5, and 6 of Table 1) with comonomer content $0.35,0.78$, and $1.60 \mathrm{~mol} \%$, respectively, were chosen to be used as macromolecular additives for the LDPE matrix, with the purpose of exploring the efficiency of copolymers with a relatively wide range compositions. Neat LDPE matrix and its mixtures with 500 and 2000 ppm of the commercial BHT antioxidant were treated under identical processing conditions and used for comparison purpose. The value of $500 \mathrm{ppm}$ is the typical amount of antioxidant added to stabilize this kind of polyolefinic materials.

Mixing conditions were chosen in order to optimize the dispersion of the macromolecular additives in the LDPE matrix meanwhile reducing, as much as possible, the oxidative and thermomechanical stresses experienced by the polymeric melt. On one hand, a mixing temperature $\left(130{ }^{\circ} \mathrm{C}\right)$ not much exceeding the melting temperature of the higher melting component allow for maintaining a quite high melt viscosity, thus favoring an even distribution and a good dispersion of the macromolecular antioxidant in the polymer matrix. On the other hand, the rotor speed of 50 rpm keeps the thermomechanical stresses at a medium level, thus avoiding a too detrimental effect on the molecular weight, which in turns affects the final properties of the ensuing blended materials. Finally, operating under $\mathrm{N}_{2}$ flux allows to minimize oxidation phenomena which can occur during mixing time.

The effect of the adopted processing conditions on the molecular weight of the LDPE matrix was checked by means of MFR and MVR measurements. MFR value changed from 0.75 $\mathrm{g} / 10 \mathrm{~min}$ of the original purchased pellets to $1.18 \mathrm{~g} / 10 \mathrm{~min}$ after the LDPE matrix experienced melt-blending treatment. By (i) approximating the LDPE here used to a linear polymer, (ii) considering that, in such a case, melt viscosity $(\eta)$ and molecular weight are related by a power law of 3.4, and (iii) applying eq 1 for the volume flow rate in a capillary of radius $R$ and length $L$, a reduction of the molecular weight of LDPE of about $12 \%$ owing to the mixing can be roughly estimated.

$$
Q=\frac{\pi R^{4} \Delta P}{8 \eta L}
$$

This molecular weight reduction can be considered to have no appreciable effect on the behavior of the materials, in terms of the investigations carried out in the present study.

While copolymers 3 and 5 resulted, as desired, well dispersed in the LDPE matrix, the blend containing sample 6, that is the copolymer richest in the $\mathrm{N}_{\mathrm{ArOH}}$ comonomer, consisted of two macroscopically distinct phases, so indicating that, for this specific family of copolymers, $1.6 \mathrm{~mol} \%$ comonomer concentration is already well above the compatibility limit of the two components of the blend. 
TABLE 2 Thermal and Thermo-oxidative Properties of Neat LDPE, Its Blends with BHT, and Ethylene/ $\mathrm{N}_{\mathrm{ArOH}}$ Copolymers

\begin{tabular}{|c|c|c|c|c|c|c|}
\hline Samples & Bound $\mathrm{N}_{\mathrm{ArOH}^{2}}{ }^{\mathrm{a}}(\mathrm{mol} \%)$ & $T_{\mathrm{D}} \mathrm{N}_{2}{ }^{\mathrm{b}}\left({ }^{\circ} \mathrm{C}\right)$ & $T_{25} \mathrm{~N}_{2}{ }^{\mathrm{c}}\left({ }^{\circ} \mathrm{C}\right)$ & $T_{\mathrm{D}} \mathrm{O}_{2}{ }^{\mathrm{b}}\left({ }^{\circ} \mathrm{C}\right)$ & $T_{25} \mathrm{O}_{2}{ }^{\mathrm{c}}\left({ }^{\circ} \mathrm{C}\right)$ & $\mathrm{OIT}^{\mathrm{d}}(\min )$ \\
\hline LDPE & - & 477 & 484 & 354 & 365 & 2.7 \\
\hline LDPE-500 BHT & - & 476 & 478 & 369 & 384 & 2.7 \\
\hline LDPE-2000 BHT & - & 475 & 474 & 371 & 380 & 6.5 \\
\hline LDPE-3 & 0.35 & 481 & 486 & 368 & 385 & 11.0 \\
\hline LDPE-5 & 0.78 & 477 & 481 & 365 & 380 & 7.4 \\
\hline LDPE-6 & 1.60 & - & - & - & - & - \\
\hline
\end{tabular}
atmosphere.

c Temperatures at which the weight loss is equal to $25 \%$ in $\mathrm{N}_{2}$ or $\mathrm{O}_{2}$ atmosphere.

\section{Thermal and Thermo-oxidative Stability of Blends Dynamic TGA}

TGA experiments were performed on film specimens of constant surface area and weight obtained from the blends by compression molding, as specified in the Experimental section. Thermal and thermo-oxidative stability of the prepared samples listed in Table 2 was first investigated by dynamic TGA (heating rate $20{ }^{\circ} \mathrm{C} \mathrm{min}^{-1}$ ) carried out, respectively, under nitrogen or oxygen atmosphere.

Under nitrogen, as expected, no noticeable differences in the degradation onset temperatures (all in the range of 475-481 ${ }^{\circ} \mathrm{C}$ ) were observed among neat LDPE, samples of LDPE containing 500 or $2000 \mathrm{ppm}$ of commercial BHT and LDPE blends containing $500 \mathrm{ppm}$ of antioxidant functionalities borne by the $\mathrm{E} / \mathrm{N}_{\mathrm{ArOH}}$ copolymers.

The dynamic TGA experiments carried out in a pure oxygen atmosphere (Fig. 1) showed the positive effect due to the presence of the polymeric additives on the degradation process of the polyethylenic matrix.

As it is clearly evident from Figure 1 and data of Table 2, the $T_{\mathrm{D} 25}$ values (temperatures at which the sample weight loss is equal to $25 \%$ ) under oxygen of the blends containing the polymeric antioxidants are shifted at temperatures 15$20{ }^{\circ} \mathrm{C}$ higher with respect to that observed for neat LDPE. The presence of the traditional BHT antioxidant in the blends leads to an increase of the oxidation resistance comparable to that of the blends containing the polymeric additives; nevertheless, this positive effect of BHT on thermo-oxidative behavior will no longer be detectable in the TGA tests carried out in isothermal mode at $180{ }^{\circ} \mathrm{C}$ (see below).

\section{Isothermal TGA}

OIT experiments were conducted by TGA in isothermal mode under $\mathrm{O}_{2}$ atmosphere at $180{ }^{\circ} \mathrm{C}$. These conditions were chosen with the aim of testing these new macromolecular antioxidants in conditions mimicking those typically used in the industrial processing of polyethylenic materials $\left(T=180{ }^{\circ} \mathrm{C}\right)$ or even worse (pure oxygen atmosphere). In Figure 2, the behaviors of the different samples analyzed are compared.
For both neat LDPE and its blend with $500 \mathrm{ppm}$ of BHT, the degradation process starts immediately after the oxygen gas is introduced in the instrument furnace. This is ascribed to the loss of the volatile low-molecular-weight additive occurring during specimen compression molding at $160{ }^{\circ} \mathrm{C}$ and/or during the heating step (under $\mathrm{N}_{2}$ ) at $180{ }^{\circ} \mathrm{C}$ in the TGA furnace, as already observed in similar experiments. ${ }^{1(\mathrm{~b}), 7(\mathrm{a})}$

Instead, good results, in terms of OIT values, were obtained using the novel macromolecular additives, whose antioxidant groups, being covalently linked to the polymer chain, are not lost during sample preparation and heating steps and are still available to perform their action of radical capture. A further confirmation of the efficiency of the polymeric additives here used with respect to the additives with low molecular weight can be deduced by observing the behavior of the blend containing 2000 ppm of BHT, which shows comparable or lower tendency to capture oxygen, despite it contains the molecular antioxidant in a concentration four times higher.

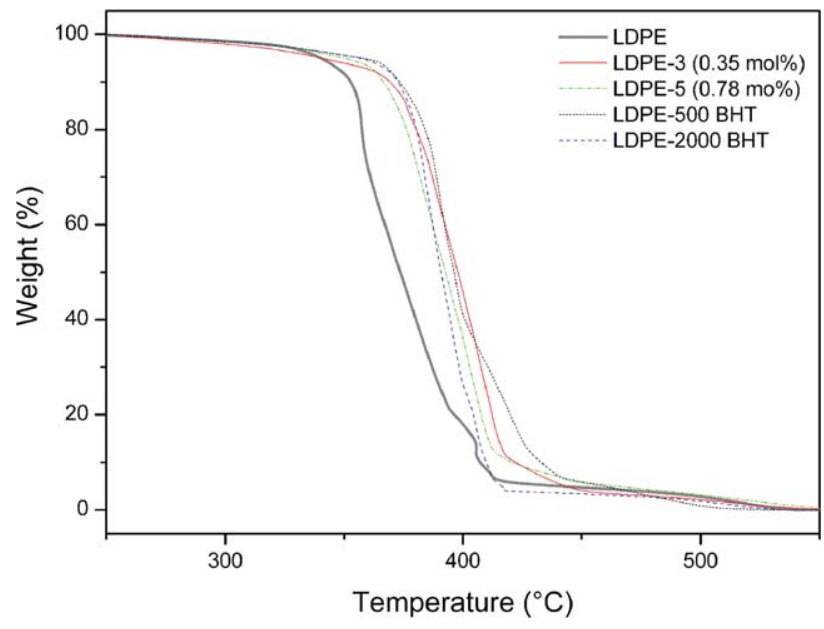

FIGURE 1 Dynamic TGA curves under $\mathrm{O}_{2}$ (heating rate $20{ }^{\circ} \mathrm{C}$ $\mathrm{min}^{-1}$ ) of LDPE blends containing the macromolecular antioxidants. Neat LDPE and LDPE containing 500 and 2000 ppm BHT are also reported for comparison. 


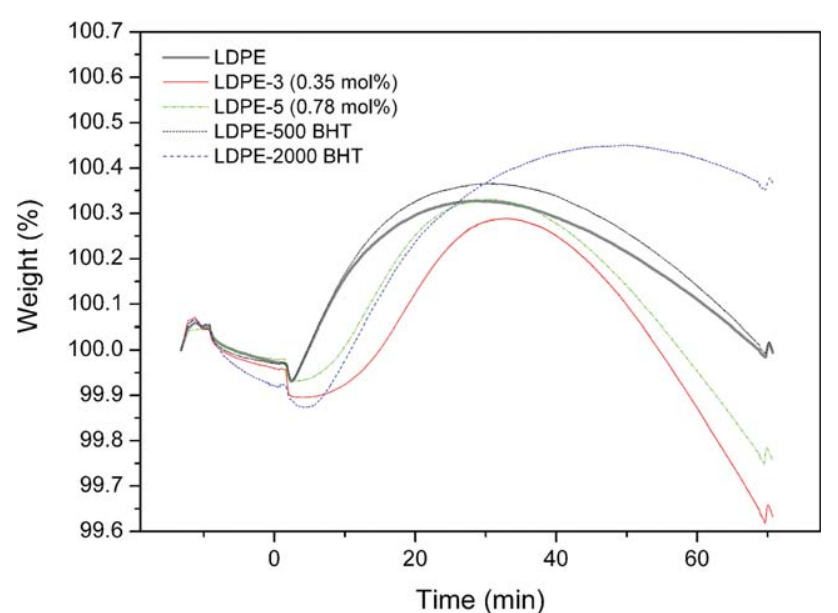

FIGURE 2 Isothermal TGA curves at $180^{\circ} \mathrm{C}$ under $\mathrm{O}_{2}$ of LDPE blends containing low-molecular weight commercial BHT antioxidant and macromolecular antioxidants. Neat LDPE is also reported for comparison.

Figure 3, which compares the OIT values of the blends containing the macromolecular additives with those of the blends containing 500 and 2000 ppm of BHT, offers a visual representation of the overall behavior of the investigated blends in the adopted isothermal conditions. Results presented in Figure 3 are also indicative of the comonomer concentration suitable for the maximization of the OIT in such kind of materials. Indeed, one can appreciate the higher efficiency of the copolymer additive with the lower comonomer concentration $(<0.4 \mathrm{~mol} \%)$ with respect, not only to the additive with higher comonomer concentration $(\sim 0.8 \mathrm{~mol}$ $\%$ ), but even to the blend containing $2000 \mathrm{ppm}$ of BHT. The fact that between the copolymeric additives the one containing the higher comonomer concentration is the less efficient

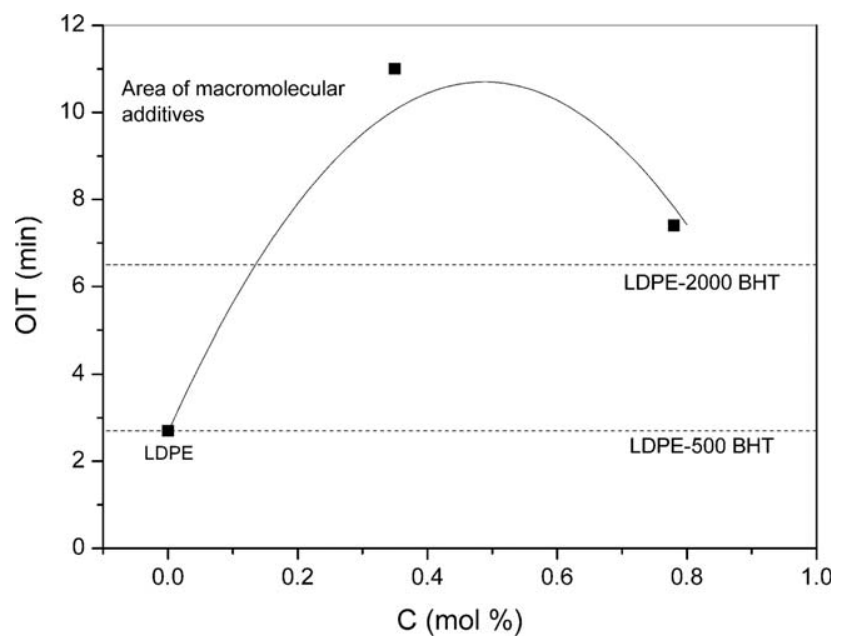

FIGURE 3 Visual representation of OIT values at $180{ }^{\circ} \mathrm{C}$ under $\mathrm{O}_{2}$ for LDPE blends containing the macromolecular antioxidants with different comonomer concentration. Dotted lines correspond to the OIT values of LDPE blends containing 500 and $2000 \mathrm{ppm}$ of BHT reported for comparison. can be explained by the reduced dispersion of the antioxidant functions in the LDPE matrix which results, consequently, less protected from oxidative degradation.

On selected film samples, further isothermal TGA experiments were carried out under $\mathrm{O}_{2}$ atmosphere at $130{ }^{\circ} \mathrm{C}$. This temperature was chosen because, being just above the melting temperature of LDPE commercial grades, is typically used for compression molding treatments, and also already used for long-term heat ageing (LTHA) tests on polyolefinic materials. ${ }^{1(\mathrm{~b})}$ In Figure 4 the isothermal TGA curves obtained at 180 and $130{ }^{\circ} \mathrm{C}$ on selected films are shown.

The OIT measurements carried out at $130{ }^{\circ} \mathrm{C}$ put in evidence that at this temperature the blend containing the macromolecular antioxidant 3 (with $\mathrm{N}_{\mathrm{ArOH}}=0.35 \mathrm{~mol} \%$ ) exhibits a very high thermo-oxidative stability (over $2 \mathrm{~h}$ in pure oxygen atmosphere), even though the substantial difference in the behavior between this blend and that containing 500 ppm of BHT is reduced when compared to that observed for the same pair at $180{ }^{\circ} \mathrm{C}$. This suggests that most of the added BHT is lost in the TGA furnace during the heating step at $180{ }^{\circ} \mathrm{C}$, whereas the temperature of $130{ }^{\circ} \mathrm{C}$ is not so detrimental for the loss of the volatile molecular antioxidant.

\section{Thermoageing and Photoageing Tests}

Ageing tests were carried out considering both temperature and light exposition as accelerating factors. In the first series of experiments, films were exposed in the oven at $70{ }^{\circ} \mathrm{C}$ for 70 days in $20 \%$ of oxygen atmosphere, in order to evaluate the thermo-oxidation in conditions milder than those used for the TGA analysis.

Thermoageing under these conditions led to some modifications in the FTIR spectra of the exposed samples and the carbonyl groups accounted for the most of the oxidation products. As an example, in Figure 5 the FTIR spectra recorded at increasing times for sample LDPE-5 $0.78 \mathrm{~mol}$ $\%)$ are reported.

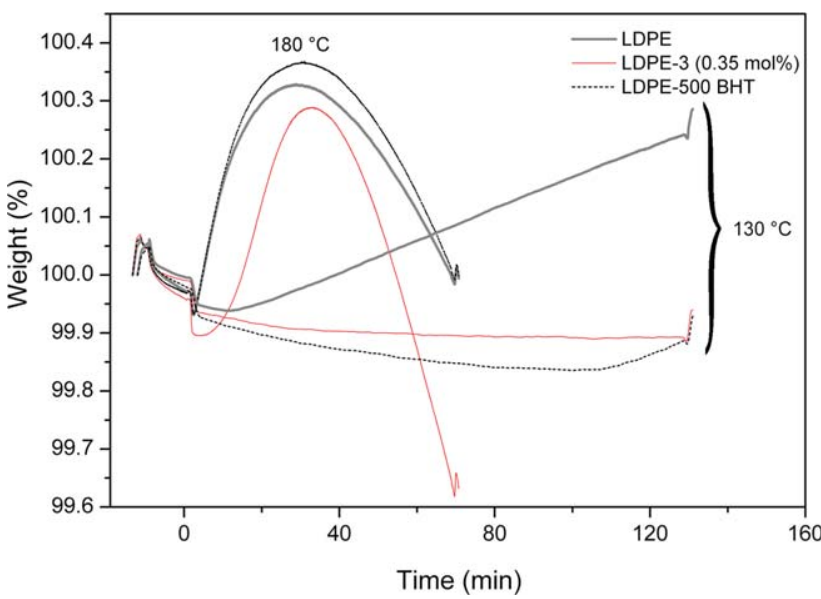

FIGURE 4 Isothermal TGA curves at different temperature (180 and $130{ }^{\circ} \mathrm{C}$ ) under $\mathrm{O}_{2}$ of LDPE blends containing low-molecular weight commercial BHT antioxidant and macromolecular antioxidant 3. Neat LDPE is also reported for comparison. 


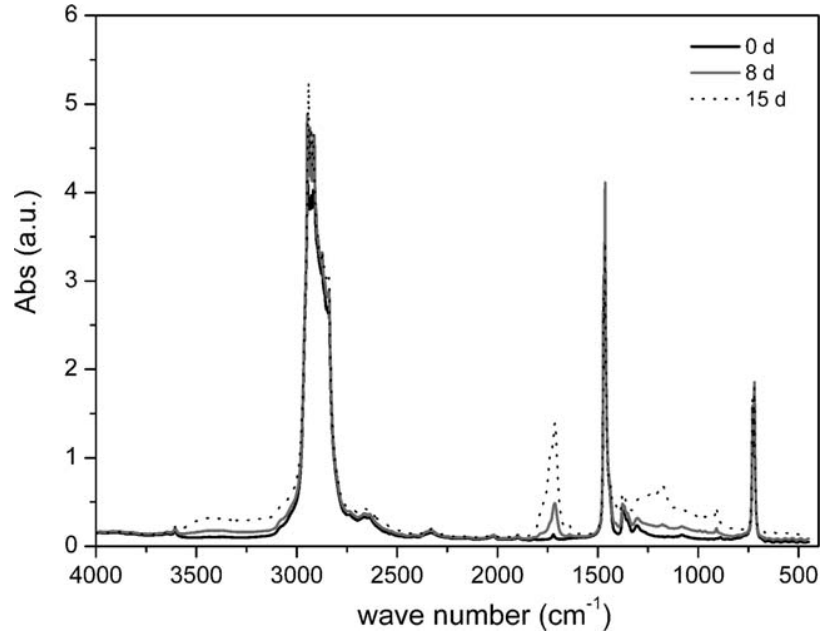

FIGURE 5 FTIR spectra of sample LDPE-5 (0.78 mol \%) during the thermoageing test in air at $70^{\circ} \mathrm{C}$.

Figure 6 shows the carbonyl index (CI) formation during the thermoageing, expressed as follows:

$$
\mathrm{CI}=\mathrm{A}_{\mathrm{C}=0} / \mathrm{A}_{2019}-\mathrm{CI}_{0}
$$

where $A_{\mathrm{C}=\mathrm{O}}$ is the peak area related to the stretching of carbonyl; $\mathrm{CI}_{0}$ is the $\mathrm{CI}$ value before the ageing experiment; $A_{2019}$ is the area of the peak at $2019 \mathrm{~cm}^{-1}$, typical of polyethylene, used as internal reference to minimize errors from sample thickness. ${ }^{14}$

The carbonyl absorption is composed of different overlapping bands corresponding to the $\mathrm{C}[\mathrm{dbond}] \mathrm{O}$ stretching in acids (at $\sim 1712 \mathrm{~cm}^{-1}$ ), ketones (at $\sim 1723 \mathrm{~cm}^{-1}$ ), aldehydes (at $\sim 1730 \mathrm{~cm}^{-1}$ ), and lactones (at $\sim 1780 \mathrm{~cm}^{-1}$ ). In the present case, carboxylic acids, responsible for the maximum at $1714 \mathrm{~cm}^{-1}$, resulted to be the main oxidation products in all the tested samples.

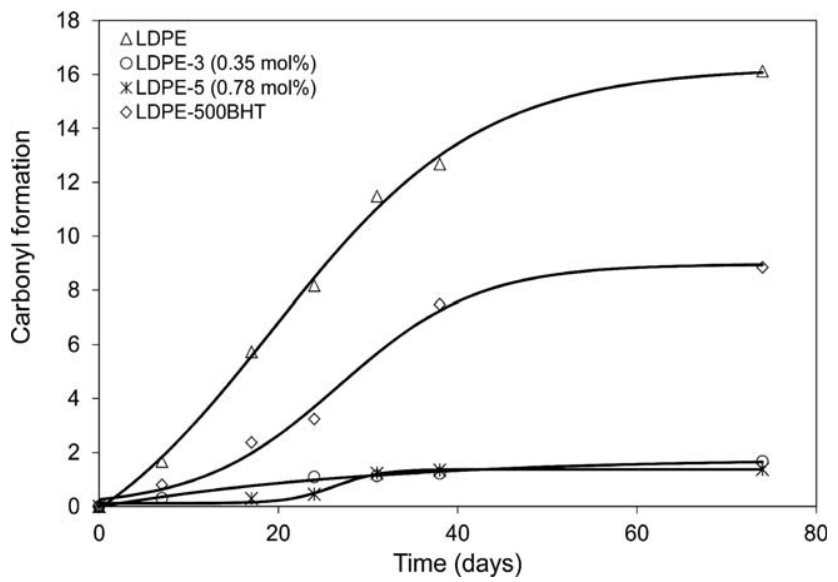

FIGURE 6 The carbonyl formation for LDPE films containing low-molecular weight commercial BHT antioxidant and polymeric antioxidants during the thermoageing test in air at $70^{\circ} \mathrm{C}$.

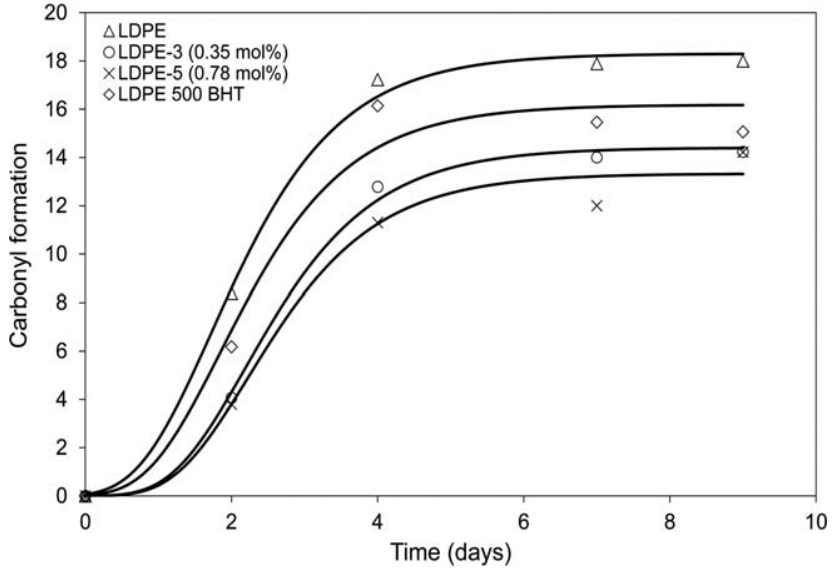

FIGURE 7 The carbonyl formation of LDPE films containing low molecular weight commercial BHT antioxidant or the polymeric antioxidants during photoageing tests at $74{ }^{\circ} \mathrm{C}$.

The action of the polymeric additive bearing the pendant antioxidant functionality was detected in the induction stage: the higher the stabilization efficiency, the longer the oxidation time, and the lower the oxidation rate. It is evident that without protection (neat LDPE) and with commercial BHT (500 ppm) the oxidation increased starting from the first week, while the carbonyl formation in LDPE blends with copolymer 3 and 5 (containing 0.35 and $0.80 \mathrm{~mol} \% \mathrm{~N}_{\mathrm{ArOH}}$ respectively) increased very slowly, eventually gaining values lower than 2. Between these two samples, no relevant differences were found in terms of thermo-oxidation in air.

The above described results on films were in line with those obtained on blends at 180 and $130{ }^{\circ} \mathrm{C}$ by TGA analysis, indicating the good thermo-oxidative resistance of LDPE when stabilized with the new macromolecular antioxidants, even after the compression molding for the preparation of films.

Samples of films were put on a black turning plate inside a ventilated black cabinet exposed to constant illumination for some days at $74{ }^{\circ} \mathrm{C}$. The contemporary exposure to light and heat caused a more rapid increase of the CI for all the samples, even if the LDPE with the polymeric additives seem to have a better resistance, especially in the first period of the exposition time (Fig. 7). Also in the case of photo-oxidation, the protection exerted by the new macromolecular additives bearing the covalently bonded hindered phenol moieties on LDPE films resulted better than that exerted by the BHT antioxidant; indeed, a longer induction time and a lower rate of carbonyl formation was observed in the former case during the first days of exposure.

\section{Specific Migration Tests}

The migration of the common molecular weight antioxidants from polyolefins into packed food is a well-known diffusional process that has been taken into account in different studies. ${ }^{15,16}$ These additives, or their degradation products, can migrate from plastics to foodstuffs during packaging or storage period. So, legislation imposes specific migration limits 
TABLE 3 Results of the Specific Migration Tests Carried Out on LDPE Films Containing BHT or Ethylene/ $\mathrm{N}_{\mathrm{ArOH}}$ Copolymers

\begin{tabular}{ccc}
\multicolumn{3}{c}{ Food Simulant } \\
\hline EtOH $95 \%$ & & $2,2,4-$ \\
$\left(40{ }^{\circ} \mathrm{C}\right.$, & EtOH $95 \%$ & Trimethylpentane \\
10 days $)$ & $\left(70^{\circ} \mathrm{C}, 2\right.$ days $)$ & $\left(20^{\circ} \mathrm{C}, 2\right.$ days $)$
\end{tabular}

\begin{tabular}{|c|c|c|c|}
\hline Samples & & Residue (mg & \\
\hline LDPE-500 BHT & $2.60 \pm 0.45$ & $2.85 \pm 0.31$ & $2.30 \pm 0.34$ \\
\hline LDPE-3 & n.d. & n.d. & n.d. \\
\hline LDPE-5 & n.d. & n.d. & n.d. \\
\hline $\begin{array}{l}\text { LDPE-3 after } \\
\text { photoageing } \\
\text { at } 74{ }^{\circ} \mathrm{C}\end{array}$ & n.d. & - & n.d. \\
\hline
\end{tabular}

n.d.: $\mathrm{BHT}, \mathrm{N}_{\mathrm{ArOH}}$ and fragments bearing the phenolic moiety not detected.

upon individual substances which have the potentiality of migrating, according to their individual toxicity. ${ }^{17}$

The migration tests on the LDPE films containing the synthesized polymeric antioxidants were carried out to evaluate their nonreleasing character and stability under different conditions of contact with substances like ethanol 95\% and 2,2,4-trimethylpentane able to simulate the extraction ability of some foodstuffs. After the contact, the residues of the food simulants were collected and analyzed by gas chromatograph-mass spectroscopy (GC-MS); the results are reported in Table 3.

Findings of Table 3 not only support the previously published data from ${ }^{13} \mathrm{C}$ NMR analysis ${ }^{8}$ suggesting the complete absence of unreacted comonomer but also excluded the presence of detectable amounts of degradation products bearing the antioxidant moiety, even after the photothermal ageing treatment. On the contrary, a migration of BHT was observed in those samples containing the commercial antioxidant. Indeed, BHT levels in ethanol at 95\% were quite close to the specific migration limit of $3 \mathrm{ppm}$, as fixed by the EU Reg $10 / 2011$ for plastic materials. ${ }^{18}$

\section{CONCLUSIONS}

In this article, we described the synthesis and the properties of a new family of "nonreleasing macromolecular additives" prepared by copolymerization of ethylene with tunable amounts of a norbornene comonomer $\left(\mathrm{N}_{\mathrm{ArOH}}\right)$ bearing a residue related to the commercial antioxidant BHT.

Copolymers with about 1 mol \% of comonomer content can be easily melt-blended with commercial LDPE due to their good compatibility with polyethylene chains. The macromolecular nature of these stabilizers prevents their extraction from the matrix during processing: a single addition of the macromolecular additives ensures protection of the polymeric material from thermal and thermo-oxidative degradation during the entire course of production of blends and films. The nonreleasing character is crucial for the properties of films especially those used for food and drug packaging. Tests of artificially induced thermal and photoageing pointed out that the films containing the polymeric stabilizers are noticeably more resistant to long-term degradation with respect to those prepared with comparable or superior concentrations of the commercial low molecular weight stabilizer BHT.

Eventually, the migration tests performed by using two specific food simulants, allowed to exclude any migration of traces of unreacted comonomer and/or of degradation products bearing the antioxidant moiety from the films to the simulants. The application of these new macromolecular additives to the development of environmentally sustainable and safe materials with zero risk of food and/or drug contamination are under investigation.

\section{ACKNOWLEDGMENTS}

This study was supported by CARIPLO Bank Fundation (Rif. 2009-2467) Project "Polymeric Additives with Covalently Bonded Stabilizers (PACk-BOSs): Design and preparation of lasting polyolefin films with no risk of food contamination and degradation" (2009-2012), and by MIUR PRIN Project 2010PFLRJR_007 “Oxidative and Free Radical Processes: New Aspects and Applications for Developing Melanin-inspired Biopolymers and Antioxidants of Biomedical and Technological Relevance (PROxi)" (2013-2015).

\section{REFERENCES AND NOTES}

1 (a) S. Al-Malaika, Effects of Antioxidants and Stabilization. In Comprehensive Polymer Science; G. Allen, J. C. Bevington, Eds.; (G. C. Eastwood, A. Ledwith, S. Russo, P. Sigwalt, volume Eds.); Pergamon Press: New York, 1989; Vol. 6, pp 539-576; (b) J. Tocháček, Polym. Degrad. Stab. 2004, 86, 385-389; (c) A. A. Hamama, W. W. Newar, J. Agric. Food Chem. 1991, 39, 10531059.

2 M. F. Pocas, T. Hogg, Trends Food Sci. Technol. 2007, 18, 219-230.

3 E. Richaud, B. Fayolle, J. Verdu, Polym. Degrad. Stab. 2011, 96, 1-11 and reference therein.

4 (a) J. A. Kuczowsky, J. G. Gillick, Rubber Chem. Technol. 1984, 57, 621 and references therein; (b) M. Curcio, F. Puoci, F. Lemma, O. I. Parisi, G. Cirillo, U. G. Spizzeri, N. Pucci, J. Agric. Food Chem. 2009, 57, 5933-5938 and reference therein.

5 (a) C. E. Wilén, J. H. Nasman, Macromolecules 1994, 27, 4051-4057; (b) C. E. Wilén, J. H. Nasman, Macromolecules 1996, 29, 8569-8575; (c) V. Busico, R. Cipullo, R. Cutillo, N. Friederihs, S. Rona, B. Wang, J. Am. Chem. Soc. 2003, 125, 1240212403.

6 (a) M. C. Sacchi, C. Cogliati, S. Losio, G. Costa, P. Stagnaro, S. Menichetti, C. Viglianisi, Macromol. Symp. 2007, 260, 21-26 (b) S. Menichetti, C. Viglianisi, F. Liguori, C. Cogliati, L. Boragno, P. Stagnaro, S. Losio, M. C. Sacchi, J. Polym. Sci. Part A: Polym. Chem. 2008, 46, 6393-6406.

7 (a) L. Boragno, P. Stagnaro, S. Losio, M. C. Sacchi, S. Menichetti, C. Viglianisi, L. Piergiovanni, S. Limbo, J. Appl. Polym. Sci. 2012, 124, 3912-3920; (b) M. C. Sacchi, S. Losio, P. 
Stagnaro, S. Menichetti, C. Viglianisi, Macromol. React. Eng 2013, 7, 84-90.

8 C. Viglianisi, S. Menichetti, G. Assanelli, M. C. Sacchi, I. Tritto, S. Losio, J. Polym. Sci. Part A: Polym. Chem. 2012, 50, 4647-4655.

9 (a) I. Tritto, L. Boggioni, D. R. Ferro, Coord. Chem. Rev. 2006 250, 212-241; (b) X. Li, Z. Hou, Chem. Rev. 2008, 252, 18421869 .

10 Data sheet Topas. Available at: http://www.topas. com/sites/default/files/files/topas_product-brochure_english.pdf (accessed February 27, 2013).

11 Data sheet Lupolen 2420 F. Available at: https://polymers.lyondellbasell.com/portal/binary/com.vignette.vps.basell.productgrade. ProductGradeFileDisplay?id=c64995b162337010VgnVCM100000646f 3c14RCRD\&type = iso (accessed February 27, 2013).

12 L. Paseiro, Compilation of Analytical Methods for Model Migrants in Foodstuffs. In Review of Analytical Methodologies;
R. Franz, C. Simoneau, Eds.; European Communities, Fraunhofer-Publica (Germany), 2006.

13 Authors' unpublished results.

14 R. Yang, J. Yu, K. Wang, Polym. Degrad. Stab. 2005, 88, 333-340.

15 C. Strandberg, A. C. Albertsson, Adv. Polym. Sci. 2008, 211, 117-157.

16 M. S. Dopico-Garciä, J. M. Lopez-Vilarin, M. V. GonzälezRodriguez. J. Agric. Food Chem. 2007, 55, 3225-3231.

17 M. S. Dopico-Garciä, J. M. Lopez-Vilarin, M. V. GonzälezRodriguez. J. Chromatogr. A 2003, 1018, 53-62.

18 COMMISSION REGULATION (EU) No 10/2011 of 14 January 2011 on plastic materials and articles intended to come into contact with food. Official Journal of the European Union. 15.1.2011. 